\title{
TECHNOLOGICAL INNOVATION AND LED LIGHTING INDUSTRY DEVELOPMENT IN CHINA
}

\author{
Lijun WANG ${ }^{1,2}$, Yongbo YU ${ }^{1}$, and Jialong XIE ${ }^{3 *}$ \\ ${ }^{1}$ School of Economics and Management, Hubei University of Technology \\ Wuhan, Hubei, 430068 China; \\ ${ }^{2}$ School of Economics and Management, Huazhong Agricultural University \\ Wuhan, Hubei, 430070, China; \\ ${ }^{3}$ School of Management, South-Central University for Nationalities \\ Wuhan, Hubei, 430074, China \\ *E-mail:xiejialong1234@126.com
}

\begin{abstract}
Current lighting industry faces a new situation, and that is rapid progress of technology in the world, rise of emerging applications, acceleration of market penetration and adjustment of competition pattern. The concentration of China's industries has been further improved. Leading enterprises have accelerated their expansion, and overseas market expansion has accelerated. Integrating mergers and acquisitions becomes the mainstream. The study combed present development situation and current problems of China's LED lighting industry. A case was chose to analyze technological innovation's effect on development of LED lighting industry, and the suggestions for further developing China's LED lighting industry were put forward. Results show that the key technology of lighting industry makes a significant breakthrough in China and optimizes product structure.
\end{abstract}

Keywords: LED, lightning industry, technological innovation

\section{INTRODUCTION}

As the global consensus on developing low carbon economy, LED lighting industry with its performance advantages in the field of saving energy and reducing consumption will usher in the rapid development of the precious opportunity [1]. At the same time, advantages of LED lighting are incomparable. As a new generation of light source in the world, LED is regarded as the most promising green lighting source in the $21^{\text {st }}$ century due to its advantages of energy saving, environmental protection, good colour rendering and long life [2].

Technological innovation is becoming a huge driving force for the rapid development of LED lights. LED industry developed rapidly and a large number of leading enterprises had sprung up in recent years. Kingsun Optoelectronic Corporation and State Key Laboratory on Integrated Optoelectronics and of Tsinghua University built Semiconductor Lighting Technology Research Institute together, which meant the enterprise of science and technology transformation and university research technology closely linked. It contributed to promoting the development of LED industry to the depth field [3]. Research and development of its core function was through construction of technology innovation platform, technology promotion and service platform, technical personnel and enterprise incubation platform, service platform, technological product with LED encapsulation and testing service centre, LED lighting applications and service centre, LED optical application and test centre for hardware support. It provided scientific research, technology, human resources and industrial investment services for 


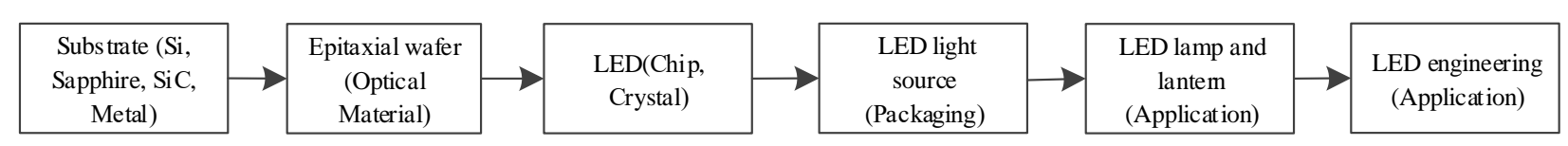

Fig.1. Industrial chain of China's LED

LED industry cluster in all aspects, and promoted steady and rapid development of LED industry [4].

\section{DEVELOPMENT STATUS ANALYSIS OF LED LIGHTING INDUSTRY IN CHINA}

\subsection{Industrial Chain}

Epitaxial wafer and chip patents in upstream are monopolized by Japanese, European and American enterprises, which will lead to excessive production of LED chips, especially in China. In the packaging process of the middle reaches, Korean enterprises rise rapidly, and good supply and demand of the industry will enhance the added value of packaging products [5]. Domestic enterprises with help of government and local advantages can compete with international well-known enterprises in application links in downstream. After years of development, China's LED industry chain has been gradually improved, and enterprises are all over the substrate, epitaxy, chip, package and application, Fig. 1. In view of the overall industrial chain, because the upstream industry has a high demand for technology and capital, it is rarely involved in domestic enterprises. Therefore, there are few enterprises and small scale characteristics in the industry [6]. By contrast, due to the downstream packaging and application of funds for enterprises and technical requirements are relatively low, this matches the characteristics of domestic enterprises, namely rather less money with weak technology. As a result, large number of enterprises engaged in packaging and application. The uneven distribution of enterprise structure leads to the majority of low-end products in China's LED industry, and the enterprises are faced with severe price pressure in the long run [7].

\subsection{Industrial Distribution}

China's LED lighting industry distribution is centralized, which has initially formed four regions of the Pearl River delta, the Yangtze River delta, southeast areas, north area, such as Beijing and Dalian. Each region basically forms relatively complete industrial chain. Four regions, namely Dalian, Shenzhen, Xiamen and Nanchang, have mature LED production base. Overall, South China's LED industry pattern of industrialization degree is higher. The Pearl River delta and the Yangtze River delta are the most concentrated areas of domestic LED lighting industry [8]. The middle and lower reaches of industry chain is more complete, which gathers more than $80 \%$ of China's related businesses. While, north area relies on a large number of universities and scientific research institutions, and product research and development strength is relatively strong.

\subsection{Industrial Scale}

In recent years, China's lighting industry generally has continued to rise. In 2016, whole output

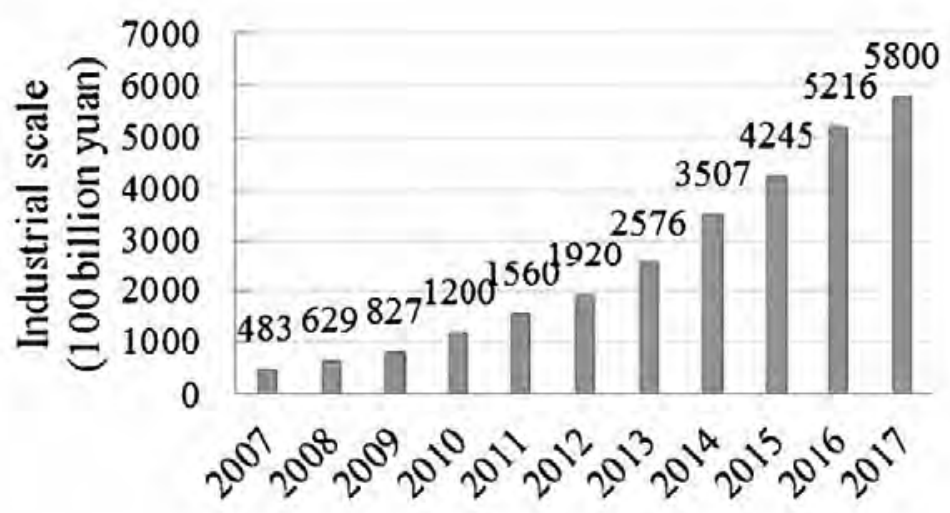

Fig.2. Industrial scale of China's LED 
value of China's lighting industry reached 521.6 billion yuan, increasing $22.8 \%$ compared with 2015 . The growth rate was slow down, shifting from "ultra-high speed" to "medium”. In 2017, overall sales of the industry were about 580 billion yuan, with $11.20 \%$ increase from 2016, shown in Fig. 2. The main reason is influenced by the significant dollar depreciation. Although export grows from $\$ 38.8$ billion in 2016 to $\$ 41.2$ billion in 2017, the contribution to overall sales growth has been limited.

\section{DEVELOPMENT PROBLEMS OF LED LIGHTING INDUSTRY IN CHINA}

At present, China's LED lighting has many applications in general lighting areas, such as tunnel lighting, road lighting, airport lighting and underground lighting. It emerges a batch of demonstration significance for application projects, such as semiconductor lighting energy-saving renovation project of the great hall, LED lighting of water cube and Shanghai World Expo pavilion, etc. However, overall market share of LED lighting is still small, and the application is still in the early stage of exploration, and there is still a long way to go for large-scale promotion. The following problems need to be solved:

1) The price of LED lighting is still too high. Although the state finance has relevant subsidies, it is still difficult to reach the degree that most engineering projects and ordinary people can accept. This requires further technological innovation and development, reducing costs and developing products that can be industrialized at a low price.

2) Current testing methods and standards of semiconductor lighting products are lagged behind, which is far behind technology and product upgrading. This leads to the result that quality of products on the market is uneven. It's difficult for users to discern whether product is good or bad, even the defective goods in circulation market share is bigger [9].

3) Industrial resources are not centralized. The market is more chaotic, and phenomenon of disordered and low-price malicious competition is widespread, which affects long-term and orderly development of the whole industry.

4) Energy saving awareness in some areas of the society is not strong enough, and the cognition of energy saving effect brought by semiconductor lighting is not yet in place. For LED lighting applications, there are also problems such as light decay, heat dissipation and light distribution, etc. Besides, system circuit board, control and drive are also included.

\subsection{Development of Related Lamps and Lanterns}

For energy-saving lamps, although energy saving is an important function, their more important status is the lamp. In modern homes and cities, the role of lights is not only illumination, but also a decoration. Different places, such as shopping malls, hotels, restaurants, supermarkets, and the family houses lighting has different requirements, and if energy-saving lamps on the appearance design, functional design, lack of innovation and breakthrough cannot take the initiative to meet the needs of the diversity of consumers, it is difficult to get market acceptance.

\subsection{Patent Problem}

At present, core patents of the LED industry are mainly controlled by several foreign companies. These companies use their respective core patent, adopt horizontal (entering several countries simultaneously) and vertical (perfect design for subsequent application) extension way, and decorate the rigorous patent worldwide network. Several international LED factories make full use of the intellectual property related to LED to achieve the goal of striking opponents and to maintain their own market position. Developed countries are taking advantage of patent weapons to seize the market of China, forming the trend and pressure of "peripheral blockage" of Chinese enterprises.

\subsection{Localization of MOCVD}

MOCVD is metal organic chemical vapour deposition equipment, which is the most critical equipment for LED epitaxial. The purchase cost is about two-thirds of that of whole LED production line. Rapid development of semiconductor lighting industry appears, and demand of the MOCVD equipment continues to increase. More than $90 \%$ of MOCVD markets around the world have been controlled by AIXTRON Company in Germany and VEECO Company in the United States. At present, China totally dependents on imports of pro- 
duction-oriented MOCVD equipment each year, and needs to invest heavily to buy such equipment. Maintenance and spare parts procurement have so much inconvenience [10].

\section{CASE STUDY}

Hannway Technology Corporate captured the beginning period of LED industry. On the one hand, it established industrialization through capital investment. On the another hand, through cooperation with scientific research institutes of colleges and universities, it introduced Shanghai Academy of Astronautics as technical support. It had breakthrough constant current driver with high reliability, high efficiency heat dissipation, integrated optical engine, LED indoor and outdoor lighting industrialization technology difficulties. It introduced a series of LED lighting products in Shanghai, in the office building, hospital, school, the subway, road, tunnel, hotel, etc. In the lighting renovation, satisfactory energy-saving effect was obtained. The good product quality, humanized design and high quality service made enterprise product to be promoted quickly in the market, and also to be paid attention by the traditional lighting giants. Under the condition of good market record, enterprise development had always been to "scientific and technological innovation" as the source of enterprise progress. Through external exchanges and cooperation, increase investment in research and development, continuously upgraded products. No matter from quality LED lighting products, performance and cost performance, the corporation always was a market leader. It had invested heavily to deepen cooperation with Shanghai Space Academy and explored new application fields. With the help of science and technology commission, scientific research got achievements successively.

At present, Hannway Technology Corporate had been awarded Shanghai metro, hospital, university and other major lighting projects through continuous market development. Construction of network construction in the field of drainage channels has also been effective. The market share gradually expands, and the sales increase year by year. It can achieve today's results, more inseparable from strategy guidance of "innovation driven, transformation development". It will bear in mind that science and technology is the first productive force, and the spirit of innovation as the soul of the enterprise.

\section{DEVELOPMENT STRATEGY CHINA'S LED LIGHTING INDUSTRY BASED ON SCIENTIFIC AND TECHNOLOGICAL INNOVATION}

\subsection{Improving Standard System for Industrial Technology and Cooperation}

On the one hand, China's LED equipment industry is a lack of complete technical standard system in the process of foreign competition. On the other hand, cooperative innovation of China's LED production equipment enterprise is also a lack of unified template and standardized system of cooperation. In industry standard system, China's government should play a fundamental role. Although there have been "CBS" system in the United States and "Muse" system in Japan, for growth of China's LED lighting industry, perfect market mechanism brings a few standard monopoly and market growth and the possibility of cooperative innovation.

Therefore, government should plan and coordinate different chain link, segmentation, local and central standards of LED industry. Through extensive international cooperation and market research, China should occupy the commanding heights of global LED industry standards. Taking construction of LED standard system as an opportunity, it should gather the standard cooperation and verification of LED equipment enterprises and production enterprises. At the same time, the standard should be kept open.

China's LED equipment enterprise technical level has got greater ascension, but due to the use of habits and credit related problems, production enterprises are not willing to cooperate with equipment enterprise. Therefore, the government needs to increase conversion efficiency of scientific research achievements, reduce the cost and risk of LED production enterprises, and fully realize the value of China's equipment enterprises.

\subsection{Strengthening Scientific and Technological Innovation to Improve Achievement Efficiency}

Due to the failure of high-end manufacturing equipment in the trial process, loss to LED manufacturers will be huge. Even equipment maker agreed to let free trial of LED production enterprises, it can affect LED manufacturing enterprises' willingness to try, due to technical workers brought 
by inappropriate use of inertia and trial enormous losses. Therefore, many LED lighting companies do not have the confidence to try out domestic equipment. Companies tend to have no confidence to try homebred MOCVD equipment, because production process also involves a lot of raw materials and artificial cost. Once waste is produced, manufacturing enterprises need to bear a great loss. Provision of free equipment and costs may be beyond capacity of device makers. Subsidy fund or a risk compensation fund should be set up to try and design a well-designed subsidy policy for equipment of China's LED manufacturers. It is encouraged to jointly build production line of LED equipment enterprises and production enterprises, which will be funded by the government or provided with other financial and administrative support to strengthen the trial intention of LED manufacturers.

\subsection{Building a Symbiosis Innovation Ecology with Leading Enterprise as the Core}

Foreign enterprises' specialized degree is high, and they generally plough in the field of LED equipment for decades deeply. Due to companies' own development ability is strong, more important is foreign industry development and cooperative innovation is leading enterprises as the core. Upstream cooperation with a batch of technical ability of small and medium-sized enterprises, colleges and universities, and research institutions is quite important. Downstream cooperation with a batch of leading enterprises and users is necessary. Development of leading enterprises returns to these small and medium-sized enterprises and partners, forming a positive cycle. Under such a symbiotic relationship, the system can continuously create blood and innovation.

Therefore, government needs to guide and support China's LED industry through strategic planning, tax incentives, credit support and special funds. Lighting enterprises should cooperate with each other to deal with the technological innovation challenge and the impact of foreign competitors. Attention should be paid to industrial chain of vertical integration and building LED equipment leading enterprises as the core, to support small and medium-sized high-tech enterprises and production application enterprises. In the process, govern- ment and other organizations should ensure service collaborative innovation pattern. It should make full use of regional potential, gather technology and application resources, reduce transaction costs and credit crisis, and extend the LED industry chain.

\section{CONCLUSIONS}

With rapid development of lighting technology, technological innovation becomes the key period of lighting industry power. In planning guidance, key technology of lighting industry in China will continuously breakthrough and optimize product structure. LED industry has expanded steadily and concentration has gradually increased. The field of application is constantly broadened. The market environment is more standardized. The business model transcends innovation, and the independent brand is bigger and stronger, which lays a solid foundation for China's development from big power of lighting industry to the great power.

\section{ACKNOWLEDGEMENT}

This work was supported by the Humanities and Social Sciences Research Youth Fund Project of Ministry of Education, "Differences and Collaboration of Innovation Gradient in Urban Agglomerations" (15YJC790108), "Research on Spatial Variation of Innovative Polarization and Cross-border Collaboration of National High-tech Zones" (16YJC630048); the National Natural Science Foundation of China "Research on Innovation Vulnerability Mechanism and Optimization Control of National High-tech Zones for System Effectiveness" (71602192); Humanities and Social Sciences Research Youth Fund Project of Hubei Provincial Department of Education, "Research on the Foundations and Approaches of Innovative Collaboration among Urban Agglomerations in the Midstream of the Yangtze River" (16Q100); Ph.D. startup gold project of Hubei University of Technology, Soft Science Project of Science and Technology Department of Hubei Province, "Investigation and collaborative mechanism design of science and technology achievements transformation in Hubei province" (2016ADC025); the Fundamental Research Funds for the Central Universities, South-Central University for Nationalities (CZQ18002). 


\section{REFERENCES}

1. Bardsley, N., Bland, S., Hansen, M., et al. Solid-state lighting R\&D plan. US Department of Energy, 2015. V20, \#2, pp.19-27.

2. Maruska, H. P., Tietjen, J.J. The preparation and properties of vapour-deposited single-crystal-line Ga N. Applied Physics Letters, 1969. V15, \#10, pp.327-329.

3. National Development and Reform Commission. The $13^{\text {th }}$ five-year plan for semiconductor lighting industry. Beijing: National Development and Reform Commission, 2017.

4. National Semiconductor Lighting Engineering R\&D and Industrial Alliance. 2017 LED industry quarterly analysis report. Beijing: National Semiconductor Lighting Engineering Research and Development and Industrial Alliance Industry Research Institute, 2017.

5. Fei, G., Bingsong, Z. Review on the development and implementation of China's green lighting project. Journal of Lighting Engineering, 2016. V27, \#4, pp.1-7.
6. Mingming, W. Interpretation of the development situation of China's semiconductor lighting industry. New Materials Industry, 2015. V5, \#3, pp.14-18.

7. Mingming, W., Shuai, Q., Xiaojia, L. Development status and trend of semiconductor lighting industry. New Material Industry, 2016. V3, \#2, pp.21-27.

8. Okon-Horodynska, E., Wisla, R., Sierotowicz, T. Leading trends of the information society technology develop-ment case study of IBM. Transformations in Business \& Economics, 2013. V12, \#2, pp.421-430.

9. Tzong-Song, W., Sheng-Wen, H. An assessment of individual and technological factors for computing validation: motivation and social processes. Revista de Cercetare si Interventie Sociala, 2015. V50, \#2, pp.156-171.

10. Diaz-Parra, O., Ruiz-Vanoye, J., Fuentes-Penna, A. A summary of the project planning of technological innovation. DYNA, V91, \#2, pp.123.

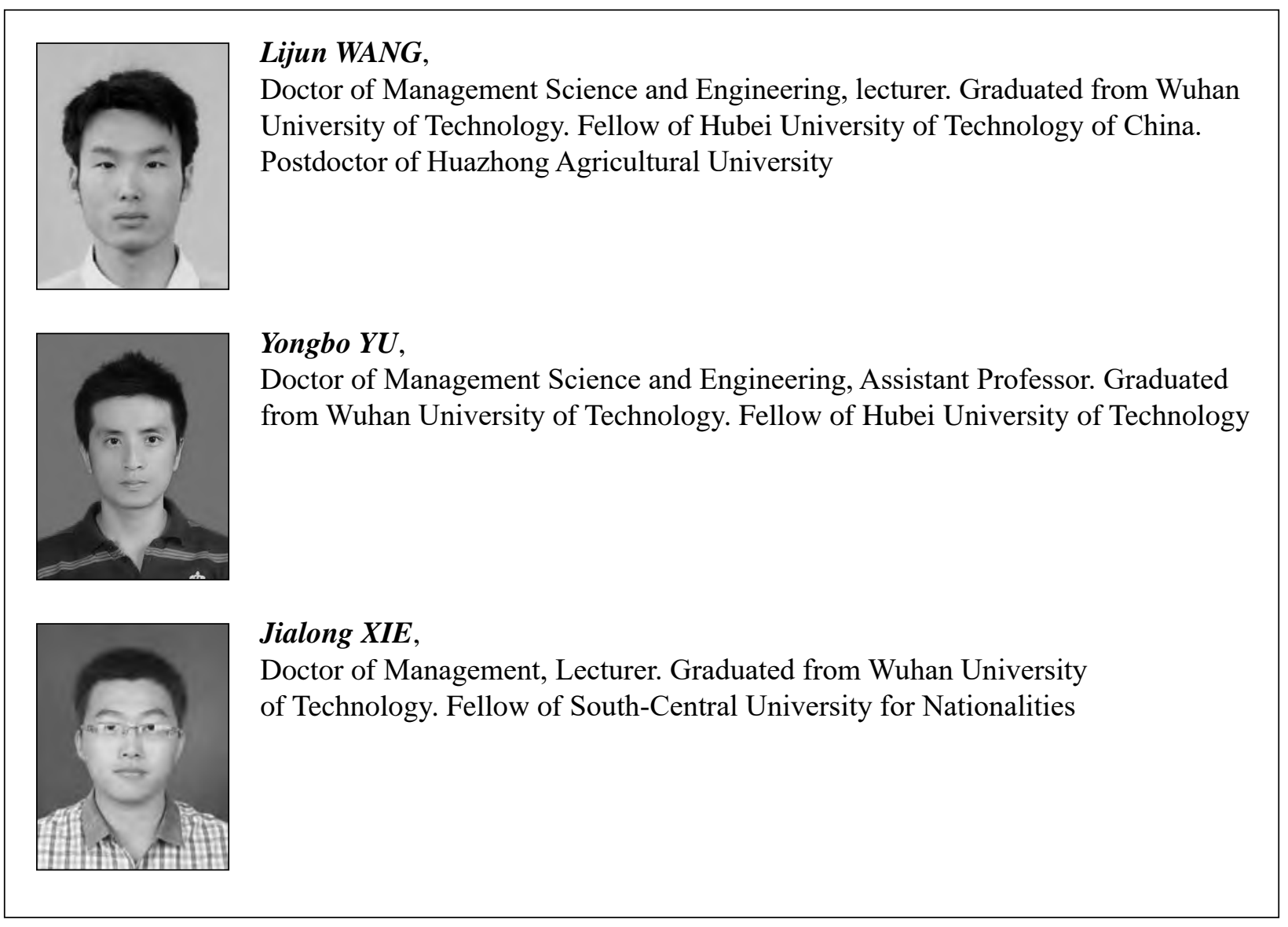

